\title{
Analisis Pengaruh Flow Rate dan Pressure pada In Situ Well Repair Menggunakan Material Polyacrylamide dengan CFD-FEM Coupling Method
}

\author{
Halida Azmi Falah, Mas Irfan P. Hidayat, Sungging Pintowantoro, dan Sonny Irawan \\ Departemen Teknik Material dan Metalurgi, Fakultas Teknologi Industri, Institut Teknologi Sepuluh \\ Nopember (ITS) \\ e-mail:irfan@mat-eng.its.ac.id
}

\begin{abstract}
Abstrak-Kebocoran pipa produksi (production tubing) dalam kegiatan eksplorasi minyak bumi dan gas alam dapat mengganggu proses produksi. Untuk itu, diperlukan metode yang tepat untuk memperbaiki kebocoran tubing tanpa menghentikan proses (shutdown). Salah satu metode perbaikan yang dapat digunakan adalah in situ well repair. In situ well repair dilakukan dengan penambalan (patching) menggunakan polimer superabsorbent jenis polyacrylamide pada flow rate dan tekanan tertentu. Pada penelitian ini dilakukan simulasi dengan CFD dan FEM untuk menganalisis pengaruh tekanan dan flow rate yang menghasilkan kemampuan in situ well repair paling optimum untuk mengatasi kebocoran tubing dengan menggunakan software ANS YS. Hasil yang diperoleh yaitu semakin besar flow rate dan tekanan, maka akan semakin besar pula kemungkinan terjadinya deformasi patch pada lokasi in situ well repair. Flow rate yang menghasilkan kemampuan in situ well repair paling optimum adalah 1000 bpd dengan nilai tekanan sebesar 36,82 Pa pada lokasi patch dengan jarak 180 inch dari dasar tubing.
\end{abstract}

Kata Kunci-In Situ Well Repair, Kebocoran Tubing, Patching, Polyacrylamide.

\section{PENDAHULUAN}

$\mathrm{K}$ EHANDALAN sistem perpipaan sangat diperlukan pada setiap industri minyak dan gas untuk mencegah terjadinya kegagalan [1]. Faktor-faktor yang menyebabkan terjadinya kegagalan pada sistem perpipaan tersebut antara lain korosi, kegagalan perawatan, kegiatan masyarakat di sekitar jalur pipa (third party activities), faktor alam, kesalahan operasional, dan kegagalan mekanik. Kegagalan yang berupa kebocoran pada pipa produksi (production tubing) dapat mengakibatkan penurunan kemampuan selama proses produksi [2].

Metode perbaikan production tubing yang telah dilakukan secara konvensional membutuhkan waktu lama, biaya mahal, dan memiliki risiko yang tinggi pada pengerjaan rig karena harus mematikan (shutdown) sumur pengeboran [3]. Untuk mengatasi kebocoran tanpa melakukan shutdown pada proses tersebut, telah dikembangkan dan dipatenkan metode perbaikan dengan cara penambalan (patch repair) oleh Drillflex
Company of Rennes di Perancis, dimulai pada tahun 1994. Pada tahun 1995 dan 1996, lebih dari empat puluh tambalan (patch) telah dipasang di sumur uji yang dangkal di Rennes dengan berbagai kondisi lubang bawah permukaan [4]. Polimer superabsorbent dengan sifat khusus yang dapat menyerap dan menjaga sejumlah besar fluida encer pada kondisi panas dan tekanan tertentu dapat digunakan untuk mencegah/membatasi aliran fluida melalui kebocoran pipa [5].

Metode patch repair bukan merupakan suatu kegiatan yang mudah untuk dilakukan pada production tubing karena memiliki parameter-parameter tertentu yang harus dikontrol, seperti flow rate dan tekanan fluida serta temperatur production tubing. Selain itu, juga dibutuhkan biaya yang banyak untuk melaksanakan metode patch repair dalam mengatasi kebocoran tubing [6]. Oleh karena itu, diperlukan penelitian berbasis simulasi untuk patch repair secara in situ tanpa melakukan shutdown pada production tubing dengan parameter flow rate dan tekanan tertentu. Penelitian ini bertujuan untuk menganalisis pengaruh flow rate dan tekanan pada lokasi in situ well repair terhadap kemungkinan terjadinya deformasi serta menganalisis flow rate dan tekanan yang menghasilkan kemampuan in situ well repair paling optimum untuk mengatasi kebocoran tubing .

\section{DASAR TEORI}

Kebocoran pada casing (casing leak) pada umumnya berhubungan dengan korosi eksternal dari formation waterbearing pada sumur yang tidak disemen. Faktor lain termasuk pemasangan tubing yang terlalu tinggi pada sumur bor, tingkat produksi fluida berlebihan, dan upaya pengendalian korosi yang buruk juga menyebabkan kebocoran pada casing [7].

Kebocoran casing dapat mengakibatkan fluida yang bergerak kehilangan sebagian energinya, yang terserap akibat adanya gesekan yang bekerja pada fluida tersebut. Hilangnya energi ini disebut sebagai kehilangan tekanan (pressure drop atau loss), dan dihitung berdas arkan perbedaan terkanan fluida tersebut di antara dua titik di pipa. [8].

Metode perbaikan kebocoran casing yang dapat digunakan adalah cement squeezing, running casing liner atau patch, shut-in polymer water, dan untuk lubang pada casing di atas 
permukaan casing shoe dilakukan pencopotan dan penggantian casing [9].

Penambalan adalah alternatif memperbaiki kebocoran casing. Casing patch yang dicoating dengan resin epoksi pada permukaan luar sebelum ditempatkan pada daerah yang diinginkan dapat digunakan untuk mengganti bagian yang rusak. Perluasan pemasangan digunakan untuk memperluas patch terhadap casing [10]. Patch terdiri dari dua bagian utam, yaitu sleeve yang terbuat dari elastomer, resin, dan fiber, yang seluruhnya diturunkan setelah terpasang, serta inflatable setting element (ISE) yang tersusun di dalam sleeve dan terhubung pada alat yang akan dijalankan. Komponen ini berfungsi sebagai kantong udara dan berisi hambatan listrik terbarui untuk memanaskan dan mempolimerisasi resin. Alat yang dijalankan berisi casing collar locator (CCL) listrik dan dihubungkan dengan kabel. Dalam CCL, terdapat pendeteksi kebocoran berupa gamma ray detector [11].

Untuk meneliti aliran multiphase dari minyak bumi dan gas alam pada kebocoran pipa vertikal, digunakan model tiga dimensi dan non-homogen untuk campuran fluida. Pada permodelan matematika, indeks $\alpha$ merepresentasikan fasa minyak kontinu dan indeks $\beta$ merepresentasikan fasa gas. Persamaan umum yang digunakan pada kasus ini yaitu:

1. Persamaan kontinuitas

$$
\begin{aligned}
& \frac{\partial\left(f_{\alpha} \rho_{\alpha}\right)}{\partial t}+\nabla \cdot\left(f_{\alpha} \rho_{\alpha} \boldsymbol{U}_{\alpha}\right)=0, \\
& \frac{\partial\left(f_{\beta} \rho_{\beta}\right)}{\partial t}+\nabla \cdot\left(f_{\beta} \rho_{\beta} \boldsymbol{U}_{\beta}\right)=0,
\end{aligned}
$$

di mana $f$ adalah fraksi volume, $\rho$ adalah densitas, dan $\boldsymbol{U}$ adalah $(u, v, w)$ vektor kecepatan.

2. Persamaan momentum

$$
\begin{aligned}
& \frac{\partial\left(f_{\alpha} \rho_{\alpha} \boldsymbol{U}_{\alpha}\right)}{\partial t}+\nabla \cdot\left[f_{\alpha}\left(\rho_{\alpha} \boldsymbol{U}_{\alpha} \otimes \boldsymbol{U}_{\alpha}\right)\right] \\
& =-f_{\alpha} \nabla p^{\prime}+\nabla \cdot\left\{f_{\alpha} \mu_{e f f, \alpha}\left[\nabla \boldsymbol{U}_{\alpha}+\left(\nabla \boldsymbol{U}_{\alpha}\right)^{\mathrm{T}}\right]\right\}+\boldsymbol{S}_{M \alpha}+\boldsymbol{D}, \\
& \frac{\partial\left(f_{\beta} \rho_{\beta} \boldsymbol{U}_{\beta}\right)}{\partial t}+\nabla \cdot\left[f_{\beta}\left(\rho_{\beta} \boldsymbol{U}_{\beta} \otimes \boldsymbol{U}_{\beta}\right)\right] \\
& =-f_{\beta} \nabla p^{\prime}+\nabla \cdot\left\{f_{\beta} \mu_{e f f, \beta}\left[\nabla \boldsymbol{U}_{\beta}+\left(\nabla \boldsymbol{U}_{\beta}\right)^{\mathrm{T}}\right]\right\}+\boldsymbol{S}_{M \beta}-\boldsymbol{D},
\end{aligned}
$$

di mana $p$ ' adalah tekanan modifikasi, $\mu_{\text {eff }}$ adalah viskositas efektif, $\boldsymbol{S}_{M}$ adalah momentum asal akibat gaya eksternal (ketika ada pengaruh gaya gravitasi), dan $\boldsymbol{D}$ adalah gaya geser yang terjadi antarfasa

Untuk Re $<1000$, koefisien geser dimodelkan berdasarkan model Schiller-Naumann:

$$
C_{D}=\frac{24}{R e}\left(1+0.15 R e^{0.687}\right),
$$

Dan untuk $\operatorname{Re} \geq 1000$, koefisien geser dianggap 0,44 di mana Re merepresentasikan bilangan Reynolds partikel, yang dimodelkan sebagai:

$$
R e=\frac{\rho_{\alpha}\left|\boldsymbol{U}_{\beta}-\boldsymbol{U}_{\alpha}\right| d_{\beta}}{\mu_{\alpha}},
$$

di mana $d_{\beta}$ merupakan diameter partikel.

\section{METODOLOGI PENELITIAN}

\section{A. Material Penelitian}

Dalam penelitian ini digunakan tubing N80 berdasarkan standar API 5CT tentang Specification for Casing and Tubing.

Tabel 1.

Spesifikasi Material Tubing N80

\begin{tabular}{lc}
\hline \hline \multicolumn{1}{c}{ Parameter } & Nilai \\
\hline Densitas & $8030 \mathrm{~kg} / \mathrm{m}^{3}$ \\
Total Elongasi Selama Pembebanan & $0,5 \%$ \\
Minimum Yield Strength & $552 \mathrm{MPa}$ \\
Maksimum Yield Strength & $758 \mathrm{MPa}$ \\
Minimum Tensile Strength & $689 \mathrm{MPa}$ \\
Modulus Young & $207.000 \mathrm{MPa}$ \\
Specific Heat & $502,48 \mathrm{~J} / \mathrm{kg} . \mathrm{K}$ \\
Thermal Conductivity & $16,27 \mathrm{~W} / \mathrm{m} . \mathrm{K}$ \\
Heat Transfer Coefficient & $150 \mathrm{~W} / \mathrm{m}^{2} . \mathrm{K}$ \\
\hline \hline
\end{tabular}

Material penambal (patching) yang digunakan adalah polimer jenis polyacrylamide.

Tabel 2.

Sifat Material Polyacrylamide

\begin{tabular}{lc}
\hline \multicolumn{1}{c}{ Parameter } & Nilai \\
\hline Densitas & $1189 \mathrm{~kg} / \mathrm{m}^{3}$ \\
Tensile Strength & $1220 \mathrm{e}+003 \mathrm{~Pa}$ \\
Elongation Break & $900 \%$ \\
Modulus Young & $7111 \mathrm{~Pa}$ \\
Poisson's Ratio & 0,48 \\
Specific Heat & $3810 \mathrm{~J} / \mathrm{kg} . \mathrm{K}$ \\
Thermal Conductivity & $0,56 \mathrm{~W} / \mathrm{m} . \mathrm{K}$ \\
\hline \hline
\end{tabular}

Fluida yang digunakan dalam penelitian ini adalah minyak bumi (crude oil) dan gas alam (natural gas).

Tabel 3.

Sifat Crude Oil dan Natural Gas

\begin{tabular}{lc}
\hline \multicolumn{2}{c}{ Crude Oil } \\
\hline \multicolumn{1}{c}{ Parameter } & Nilai \\
\hline Densitas & $960 \mathrm{~kg} / \mathrm{m}^{3}$ \\
Specific Heat & $1880 \mathrm{~J} / \mathrm{kg} \cdot \mathrm{K}$ \\
Thermal Conductivity & $0,12 \mathrm{~W} / \mathrm{m} . \mathrm{K}$ \\
Viskositas & $0,048 \mathrm{~kg} / \mathrm{ms}$ \\
Molecular Weight & $258,19 \mathrm{~kg} / \mathrm{kmol}$ \\
\hline \multicolumn{1}{c}{ Parameter } & Nilai \\
\hline \multicolumn{1}{c}{ Pas } & $0,6679 \mathrm{~kg} / \mathrm{m}^{3}$ \\
\hline Densitas & $-7,489518 \mathrm{e}+07 \mathrm{~J} / \mathrm{kmol}$ \\
Standard State Enthalpy & $0,0332 \mathrm{~W} / \mathrm{m} . \mathrm{K}$ \\
Thermal Conductivity & $1,087 \mathrm{e}-05 \mathrm{~kg} / \mathrm{m} . \mathrm{s}$ \\
Viskositas & $16,04303 \mathrm{~kg} / \mathrm{kmol}$ \\
Molecular Weight &
\end{tabular}

\section{B. Peralatan Penelitian}

Peralatan yang digunakan untuk penelitian tugas akhir ini berupa perangkat lunak (software) berbasis metode elemen 
hingga, yaitu ANSYS Workbench 17.1 dengan modul Fluent yang digunakan untuk memodelkan fluida dan modul Mechanical Static Structural untuk memodelkan tubing N80.

\section{Geometri Penelitian}

Geometri yang digunakan pada penelitian ini berupa tubing produksi berbentuk silinder dengan lima lubang paralel yang terletak sejajar di sisi depan. Dimensi pipa dan lubang ditunjukkan pada tabel berikut.

Tabel 4.

Dimensi Geometri Penelitian

\begin{tabular}{lc}
\hline \multicolumn{1}{c}{ Dimensi } & Nilai \\
\hline Panjang pipa & 216 inch \\
Diameter luar pipa & 4,5 inch \\
Diameter dalam pipa & 4,229 inch \\
Ketebalan pipa & 0,271 inch \\
Diameter lubang & 0,15 inch \\
Jarak antar lubang & 36 inch \\
\hline \hline
\end{tabular}

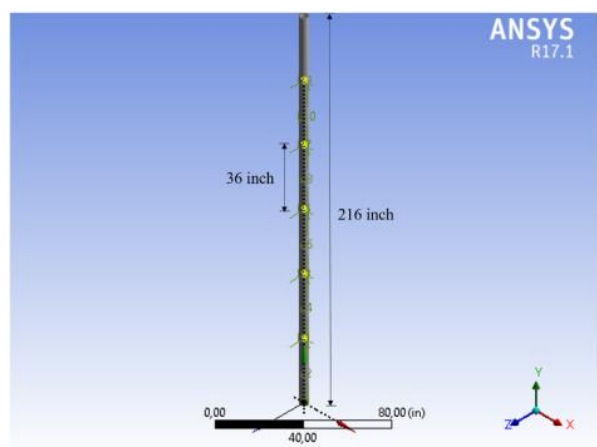

Gambar 1. Geometri Pipa Penelitian

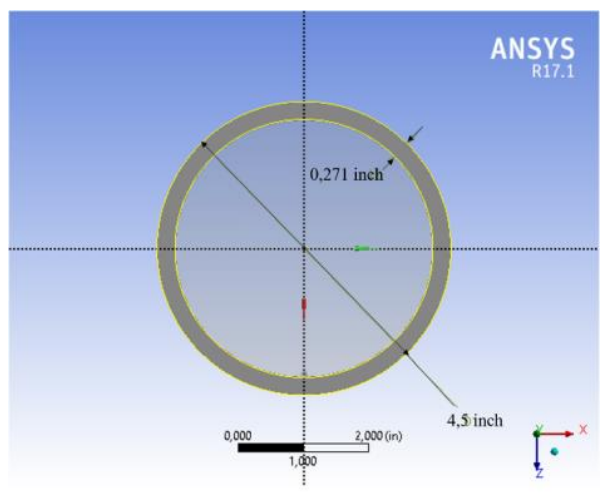

Gambar 2. Diameter dan Ketebalan Pipa

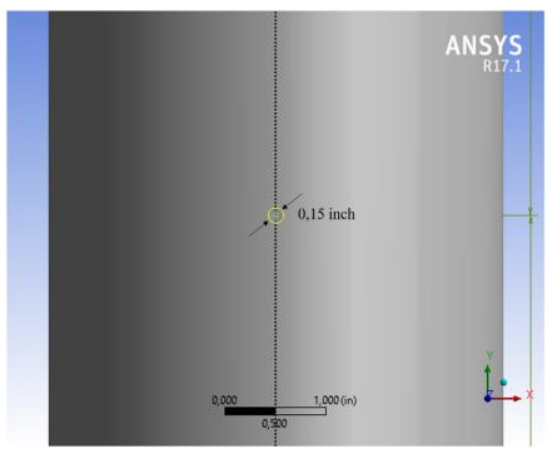

Gambar 3. Diameter Lubang

\section{Variabel Penelitian}

Dalam penelitian ini, digunakan beberapa variasi, di antaranya variasi flow rate, sensitivitas meshing, serta kedalaman lokasi kebocoran. Flow rate divariasikan sesuai dengan data lapangan pengeboran minya, sebesar $1000 \mathrm{bpd}$, $1050 \mathrm{bpd}, 1100 \mathrm{bpd}, 1150 \mathrm{bpd}$, dan $1200 \mathrm{bpd}$. Jenis meshing yang digunakan adalah meshing kasar, medium, dan halus untuk menganalisis sensitivitas yang ditimbulkan. Lokasi kebocoran yang digunakan pada permodelan ini adalah pada kedalaman 36 inch, 72 inch, 108 inch, 144 inch, dan 180 inch dari dasar sambungan tubing untuk mengetahui nilai tekanan pada daerah kebocoran dengan kedalaman yang berbeda.

\section{E. Setup Permodelan \\ 1) Modul Fluent}

Analisis fluida yang mengalir dalam pipa dilakukan menggunakan ANSYS modul Fluent. Kondisi umum yang dijalankan yaitu tipe pressure based dengan keadaan steady. Percepatan gravitasi sebesar $-9,81 \mathrm{~m} / \mathrm{s}^{2}$ terjadi sepanjang sumbu-y. Aliran minyak bumi dan gas alam terjadi secara multiphase dalam keadaan laminar. Dengan boundary condition berupa velocity inlet berdasarkan perhitungan nilai kecepatan yang diperoleh dari nilai flow rate, diperoleh distribusi tekanan relatif sepanjang geometri tubing yang menunjukkan adanya kehilangan tekanan (pressure drop).

\section{2) Modul Static Structural}

Analisis structural tubing N80 dilakukan dengan ANSYS modul Static Structural. Nilai tekanan dari modul Fluent akan diimport sebagai input pembebanan yang terjadi sepanjang geometri tubing. Untuk menahan pengaruh pembebanan tekanan agar tetap stabil, didefinisikan daerah fixed support yang terletak di kedua ujung tubing. Dinding tubing bagian dalam didefinisikan sebagai daerah fluid solid interface, yang merupakan bagian tubing yang terkena pengaruh aliran fluida. Hasil yang diperoleh yaitu deformasi sepanjang geometri tubing dan patch akibat pembebanan tekanan.

\section{HASIL DAN DISKUSI}

Fluida diasumsikan merupakan minyak bumi dan gas alam yang dapat tercampur secara sempurna yang mengalir pada tubing N80 secara vertikal ke atas dari dasar tubing yang didefinisikan sebagai inlet. Fluida diasumsikan bersifat Newtonian (memiliki viskositas konstan pada suhu tertentu), incompressible (tidak dapat dimampatkan), is othermal (memiliki temperatur konstan sepanjang tubing), serta memiliki sifat fisik dan kimia konstan. Aliran fluida tersebut diasumsikan berada pada kondisi steady state.

\section{A. Pengaruh Flow Rate terhadap Pressure Drop}

Nilai pressure drop pada sensitivitas meshing dari masingmasing variasi flow rate ditunjukkan pada gambar berikut. 


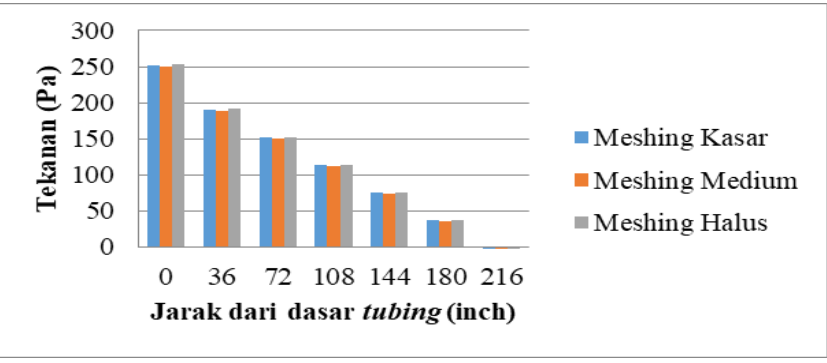

(a) Variasi Flow Rate 1000 bpd

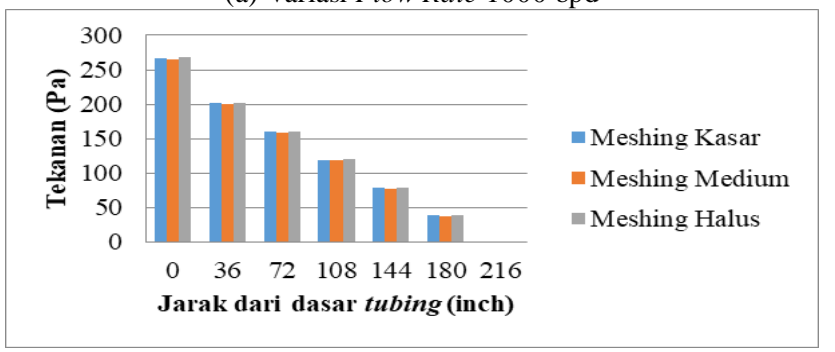

(b) Variasi Flow Rate 1050 bpd

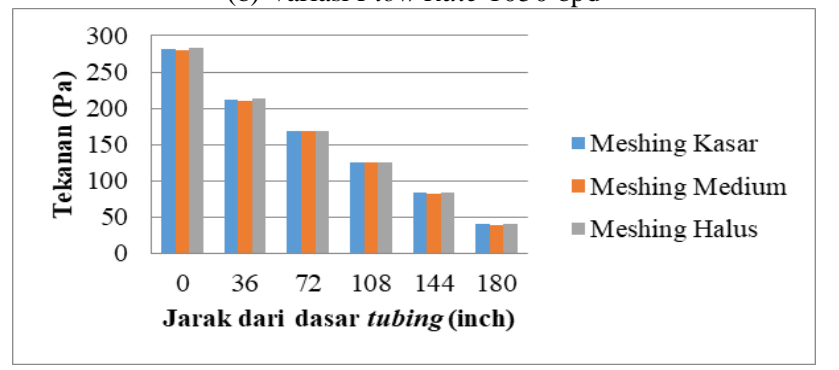

(c) Variasi Flow Rate 1100 bpd

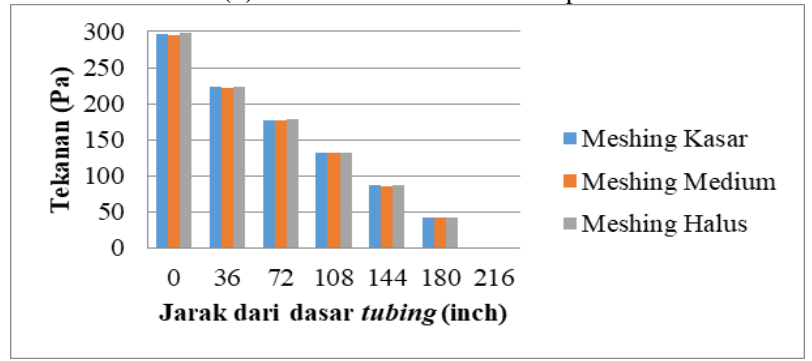

(d) Variasi Flow Rate 1150 bpd

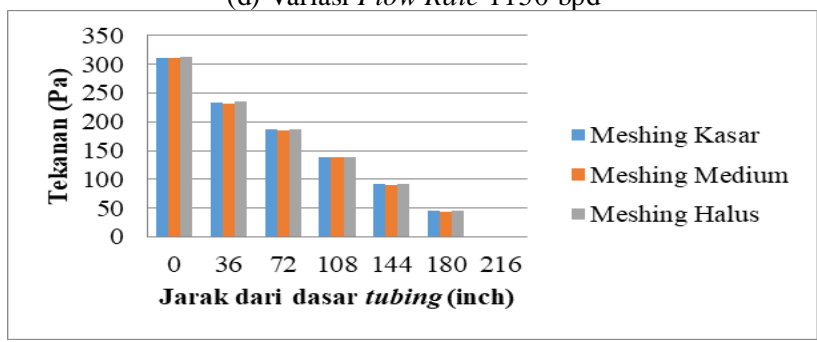

(e) Variasi Flow Rate 1200 bpd

Gambar 4. Grafik Pressure Drop dengan Variasi Flow Rate

Berdasarkan grafik-grafik tersebut, dapat diketahui bahwa tekanan relatif pada sensitivitas meshing yang berbeda akan menghasilkan nilai yang berbeda pula [12]. Tekanan awal akibat pengaruh variasi flow rate memiliki nilai yang hampir sama untuk masing-masing sensitivitas. Nilai tersebut tidak menunjukkan perbedaan yang terlalu signifikan.

Pengaruh flow rate paling besar terjadi pada meshing halus, pada lokasi awal terjadinya aliran fluida. Selanjutnya terjadi pressure drop sepanjang geometri tubing yang hampir sama pada ketiga jenis sensitivitas meshing.

Nilai pressure drop paling besar akibat pengaruh masingmasing flow rate terjadi pada geometri dengan meshing halus. Hal tersebut menunjukkan bahwa meshing halus memiliki sensitivitas paling tinggi terhadap input flow rate yang diberikan. Sehingga akan mengakibatkan ketelitian yang tinggi pada nilai yang dihasilkan. Dapat diketahui bahwa kualitas kekasaran permukaan pada meshing menunjukkan ketelitian dan kepekaan geometri terhadap input yang diberikan [13].

\section{B. Deformasi Akibat Pengaruh Pembebanan Tekanan}

Distribusi deformasi akibat pengaruh pembebanan tekanan pada sensitivitas meshing dari masing-masing variasiflow rate ditunjukkan pada gambar berikut.

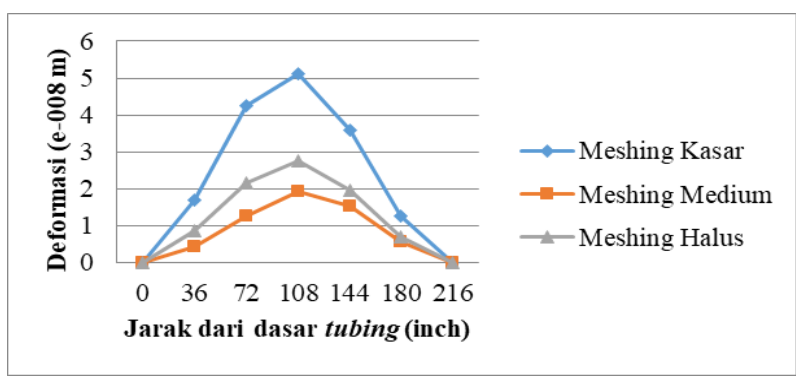

(a) Variasi Flow Rate 1000 bpd

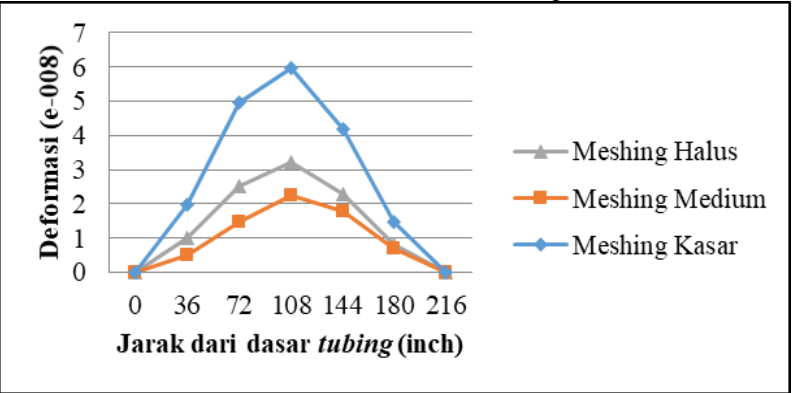

(b) Variasi Flow Rate $1050 \mathrm{bpd}$

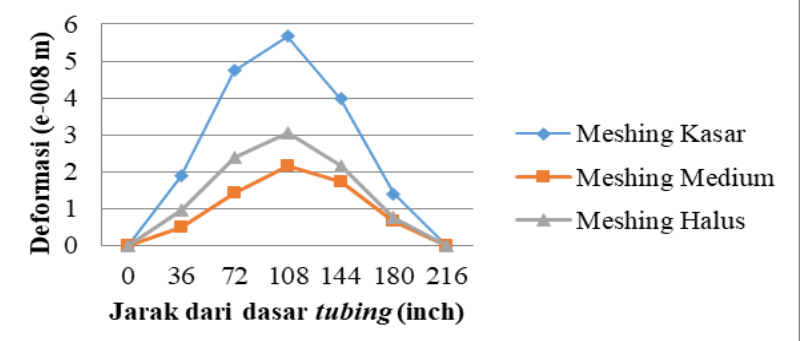

(c) Variasi Flow Rate 1100 bpd

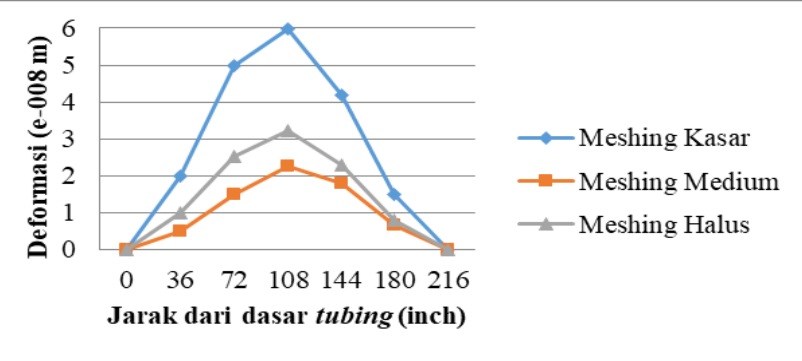

(d) Variasi Flow Rate 1150 bpd 


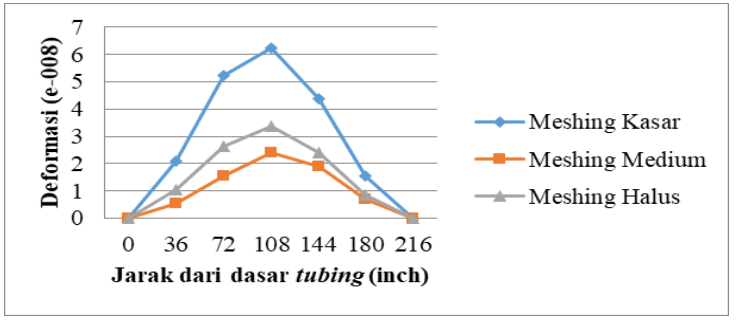

(e) Variasi Flow Rate 1200 bpd

Gambar 5. Distribusi Deformasi pada masing-masing Variasi Flow Rate

Berdasarkan pembebanan tekanan yang diberikan akibat pengaruh flow rate sepanjang geometri tubing, dapat diketahui bahwa deformasi paling besar terjadi pada jarak 108 inch dari dasar tubing pada geometri masing-masing variasi meshing. Hal tersebut diakibatkan karena patch yang terletak pada jarak 108 inch merupakan lokasi terjauh dari fixed support ujung sambungan atas maupun bawah [14]. Meskipun tekanan yang terjadi pada daerah tersebut tidak sebesar tekanan pada dasar tubing yang merupakan lokasi awal terjadinya aliran fluida, tetapi kemampuan geometri dalam menahan pengaruh pembebanan yang diberikan tidak cukup kuat sehingga deformasi terjadi secara maksimum [15].

Pada ujung bawah sambungan tubing yang disebut sebagai lokasi 0 inch dan ujung atas sambungan tubing yang disebut sebagai lokasi 216 inch, deformasi yang terjadi yaitu sebesar 0 atau dapat dikatakan tidak terjadi deformasi. Hal tersebut karena ujung atas dan ujung bawah sambungan tubing merupakan lokasi di mana fixed support diterapkan [16].

\section{Analisis Flow Rate dan Tekanan Optimum}

Dalam simulasi ini, fluida yang diasumsikan mengalir secara laminar dan dalam kondisi steady state diberikan variasi flow rate yang telah dikonversi menjadi input kecepatan sehingga dapat bergerak secara vertikal ke atas sepanjang tubing yang berukuran panjang 216 inch atau setara dengan 5,4864 meter dan diameter luar 4,5 inch dengan ketebalan 0,271 inch.

Di sisi bagian depan tubing, diasumsikan terjadi kebocoran pada 5 titik dengan ketinggian berbeda yang terletak secara paralel. Lubang kebocoran tersebut dibuat seragam dengan asumsi diameter sebes ar 0,15 inch. Selanjutnya lubang tersebut telah dilakukan patching menggunakan material polyacrylamide dengan daya kohesi sebesar 39800 joule/mol sehingga diperoleh tegangan sebesar 665,8 Mpa [17].

Variasi flow rate yang disimulasikan yaitu sebes ar 1000 barrel per hari hingga 1200 barrel per hari. Variasi tersebut dilakukan berdasarkan data lapangan dari aliran fluida pengeboran. Flow rate tersebut akan menghasilkan nilai penurunan tekanan sepanjang geometri vertikal tubing. Hal tersebut dilakukan untuk menunjukkan kemampuan pelekatan patch ditinjau dari pengaruh tekanan yang dihasilkan selama aliran fluida.

Berdasarkan data-data flow rate dan tekanan serta pengaruhnya terhadap terjadinya deformasi pada lokasi patch, dapat diketahui bahwa geometri dengan meshing halus memiliki sensitivitas paling tinggi terhadap input flow rate yang diberikan.

Variasi flow rate yang diberikan akan menghasilkan nilai deformasi yang beragam. Hasil yang diperoleh dari variasi flow rate tersebut yaitu semakin besar flow rate, maka akan semakin besar pula kemungkinan terjadinya deformasi patch pada lokasi in situ well repair. Hal tersebut ditunjukkan dari nilai deformasi maksimum yang diperoleh pada masing-masing variasiflow rate.

Aliran fluida pada pipa vertikal akan mengalami penurunan tekanan sepanjang geometri pipa yang dilalui fluida tersebut. Adanya kehilangan tekanan (pressure loss) pada aliran fluida melalui pipa vertikal diakibatkan oleh adanya gesekan yang terjadi di sepanjang permukaan pipa [18]. Sebenarnya tekanan tersebut tidak hilang, hany a saja karena terjadi tegangan geser, sebagian energinya akan berubah dalam bentuk lain seperti energi panas, bunyi, dan lain-lain [18].

Seiring dengan panjangnya pipa yang dilalui, maka nilai pressure drop akan semakin besar [19]. Hal ini sesuai dengan hasil simulasi penelitian yang menunjukkan bahwa tekanan pada lubang yang berjarak 180 inch dari dasar tubing mengalami penurunan yang paling besar.

Deformasi pada patch yang dihasilkan dari variasi tekanan ters ebut akan meningkat apabila tekanannya bertambah besar. Semakin besar tekanan, maka akan semakin besar pula kemungkinan terjadinya deformasi patch pada lokasi in situ well repair [20]. Namun, keberadaan fixed support juga akan mempengaruhi kemungkinan terjadinya deformasi.

Pada umumnya, kemungkinan terjadinya deformasi patch terbesar berada pada lokasi terjauh dari penahan pembebanan yang diberikan. Dalam hal ini, lokasi tersebut berada pada jarak 108 inch dari fixed support di ujung atas dan bawah sambungan tubing. Kondisi tersebut merupakan kondisi tidak ideal karena dengan pengaruh tekanan yang tidak terlalu besar, deformasi tetap dapat terjadi.

Kondisi paling ideal pada in situ well repair yang telah disimulasikan berdasarkan pengaruh flow rate dan tekanan dalam penelitian ini adalah dengan minimum flow rate yang diberikan, yaitu sebesar 1000 bpd. Deformasi minimum yang terjadi pada patch yaitu sebesar 1,953e-008 m. Nilai tekanan yang menghasilkan deformasi minimum tersebut yaitu sebesar 36,82 $\mathrm{Pa}$.

\section{KESIMPULAN}

Telah dilakukan penelitian berbas is simulasi tentang metode perbaikan tubing secara in situ menggunakan software ANSYS dengan memvariasikan flow rate sesuai data proses pengeboran, sensitivitas meshing pada geometri, serta lokasi kebocoran pada tubing. Berdasarkan nilai flow rate dan tekanan yang diperoleh, diketahui bahwa semakin besar flow rate dan tekanan, maka akan semakin besar pula kemungkinan terjadinya deformasi patch pada lokasi in situ well repair.

Flow rate yang menghasilkan kemampuan in situ well repair paling optimum adalah 1000 bpd dengan nilai tekanan sebesar 36,82 Pa pada lokasi patch dengan jarak 180 inch dari dasar tubing.

Pada penelitian selanjutnya, sangat disarankan untuk melakukan penelitian dengan menggunakan analisis secara transient atau dynamic explicit agar diperoleh hasil yang lebih presisi. Selain itu juga disarankan untuk melakukan penelitian 
untuk kemungkinan terjadinya kebocoran tubing pada tingkat kedalaman yang lebih bervariasi serta melakukan penelitian lebih lanjut mengenai material patch lain agar dapat diketahui material yang paling sesuai dengan kondisi kebocoran tubing.

\section{LAMPIRAN}

Perhitungan input velocity inlet berdasarkan nilai flow rate pada proses pengeboran minyak bumi dan gas alam. Diketahui flow rate pada proses pengeboran minyak bumi dan gas alam berkisar antara 1000 hingga 1200 barrel per hari dan Luas penampang alas pipa bagian dalam sebesar 12,304 inch ${ }^{2}$.

$$
\begin{gathered}
\text { Area }=12,304 \mathrm{inch}^{2}=0,00793804864 \mathrm{~m}^{2} \\
\text { velocity }=\frac{\text { flow rate }}{\text { area }}
\end{gathered}
$$

Variabel 1

$$
\begin{aligned}
\text { Flow rate } & =1000 \mathrm{barrel} \text { per hari } \\
& =0,0018 \mathrm{~m}^{3} / \mathrm{s} \\
\text { Velocity } & =\frac{0,0018 \mathrm{~m} 3 / \mathrm{s}}{0,00793804864 \mathrm{~m} 2} \\
& =0,2267559802 \mathrm{~m} / \mathrm{s}
\end{aligned}
$$

Variabel 2

$$
\begin{aligned}
\text { Flow rate } & =1050 \text { barrel per hari } \\
& =0,00189 \mathrm{~m}^{3} / \mathrm{s} \\
\text { Velocity } & =\frac{0,00189 \mathrm{~m}^{3 / \mathrm{s}}}{0,00793804864 \mathrm{~m} 2} \\
& =0,2380937792 \mathrm{~m} / \mathrm{s}
\end{aligned}
$$

Variabel 3

$$
\begin{aligned}
\text { Flow rate } & =1100 \text { barrel per hari } \\
& =0,00198 \mathrm{~m}^{3} / \mathrm{s} \\
\text { Velocity } & =\frac{0,00198 \mathrm{~m} 3 / \mathrm{s}}{0,00793804864 \mathrm{~m} 2} \\
& =0,2494315782 \mathrm{~m} / \mathrm{s}
\end{aligned}
$$

Variabel 4

$$
\begin{aligned}
\text { Flow rate } & =1150 \text { barrel per hari } \\
& =0,00207 \mathrm{~m}^{3} / \mathrm{s} \\
\text { Velocity } & =\frac{0,00207 \mathrm{~m} 3 / \mathrm{s}}{0,00793804864 \mathrm{~m} 2} \\
& =0,2607693772 \mathrm{~m} / \mathrm{s}
\end{aligned}
$$

Variabel 5

$$
\begin{aligned}
\text { Flow rate } & =1200 \text { barrel per hari } \\
& =0,00216 \mathrm{~m}^{3} / \mathrm{s} \\
\text { Velocity } & =\frac{0,00216 \mathrm{~m} 3 / \mathrm{s}}{0,00793804864 \mathrm{~m} 2} \\
& =0,2721071762 \mathrm{~m} / \mathrm{s}
\end{aligned}
$$

\section{UCAPAN TERIMA KASIH}

Penulis mengucapkan terima kasih kepada Allah SWT yang telah merahmati selama penulisan. Penulis juga mengucapkan terima kasih kepada orang tua, keluarga, serta sahabat-sahabat yang selalu memberikan dukungan dan motivasi hingga terselesaikannya penelitian ini.

\section{DAFTAR PUSTAKA}

[1] Z. Hendrizal, I. P., \& Djunaidi, "Analisis Risiko pada Pipa 6" Crude Oil SP PDT I - SP Tambun di PT Pertamina EP Region Jawa Field T ambun.," Universitas Indonesia, 2013.
Superabsorbent Polymers for Sealing Tubing Leaks. Bandar Seri Iskandar: Universiti Teknologi Petronas, 2016.

[3] J. R. Styler, J. W., Al-Suwailem, S. S., Akhnoukh, R. L. \& Leighton, A Unique Rigless Casing Leak Repair, Ghawar Field, Saudi Arabia. Saudi Arabia: Society of Petroleum Engineers, 2001.

[4] S. R. Sousa, J. V., Sodre, C. H., Lima, A. G., \& Neto, "Numerical Analysis of Heavy Oil-Water Flow and Leak Detection in Vertical Pipeline," Adv. Chem. Eng. Sci., no. 915, 2013.

[5] M. M. Genedy, M., Kandil, U. F., Matteo, E. N., Stormont, J., \& Taha, "A New Polymer Nanocomposite Repair Material for Restoring Wellbore Seal Integrity," Int. J. Greenh. Gas Control, pp. 290-297, 2016.

[6] U. S. S. T. Products, Oil Country Tubular Goods. Pittsburgh. USA: Steel Tubular Products, 2014.

[7] H. Devold, Oil and Gas Produsction Handbook: An Introduction to Oil and Gas Production, Transport, Refining, and Petrochemical Industry. ABB Oil and Gas, 2013.

[8] O. J. Carolina Andrade de Sousa, "Influence of Oil Leakage in the Pressure and Flow Rate Behaviors in Pipeline," Lat. Am. J. Energy Res., pp. 17-29, 2017.

[9] H. P. Chris Alexander, "Modeling Leakage in a Fuel Transfer Pipeline Using Computational Fluid Dynamics Techniques.," in ASME Pressure Vessels and Piping Division Conference, 2005, pp. 1-11.

[10] Y. Li, X., Ji, H., \& Li, "Fluent in the Simulation of the Application of the Natural Gas Leakage," in International Conference on Mechanical Engineering and Material Science, 2012, pp. 690-692.

[11] G. Hermadi, "Analisis Perbandingan Efektifitas Model Fluida Bingham dan Power Law dalam Optimasi Flow Rate Pompa dan Pengangkatan Cutting," 2010.

[12] M.-L. Todorovic, J., Raphaug, M., Lindeberg, E., Vralstad, T., \& Buddensiek, "Remediation of Leakage through Annular Cement Using a Polymer Resin: a Laboratory Study," Energy Procedia, pp. 442-449, 2016.

[13] L.-B. Ouyang, “A Novel Approach to Detect Tubing Leakage in Carbon Dioxide (CO2) Injection Wells via an Efficient Annular Pressure Monitoring," Open Pet. Eng. J., pp. 8-15, 2015.

[14] T. Malau, J., \& Sitepu, “). Analisa Pressure Drop pada Sistem Perpipaan Fuel Oil Boiler pada PT PLN Pembangkitan Sumatera Bagian Utara Sicanang-Belawan dengan Menggunakan Pipe Flow Expert,” J. e-Dinamis, vol. 3, pp. 164-171, 2012.

[15] W. P. Negara, "Perbandingan Analisis Pressure Drop pada P ipa Lengkung 90o Standar ANSI B36.10 dengan COSMOSfloWorks 2007," J. Tek. Mesin Univ. Gunadarma, pp. 1-13, 2010.

[16] A. T. L. S. Riza, "Pengembangan Perangkat Lunak untuk Simulasi Estimasi Volume Kebocoran Minyak," J. Pendidik. Teknol. Inf. dan Komun., pp. 33-34, 2009.

[17] R. K. Khandka, Leakage Behind Casing. Norway: NTNU, 2007.

[18] A. S. Samuel Eshorame Sanni, "Modeling of Sand and Crude Oil Flow in Horizontal Pipes during Crude Oil Transportation," $J$. Eng., pp. 1-7, 2014.

[19] G. W. Shuwei Wang, "CFD for Multiphase Flow Transport of Buried Crude Oil Pipelines Leakage," Int. Conf. Pipelines Trenchless Technol., pp. 861-874, 2012.

[20] Y. F. Tianhan Xu, "Evaluation of Mechanical Properties and Microstructures of Casing-Drilling Steels," Adv. Mater. Res., pp. 674-677, 2010. 